\title{
Racial History in India
}

$\mathrm{F}^{\mathrm{o}}$ OR the first time since 1901 , the report on the Census of India includes a volume of ethnographic appendixes*. It is a welcome, and as those who are familiar with the earlier volumes of the report will agree, a very necessary addition, at least in so far as it deals with the question of racial distributions.

Of the two parts into which the volume is divided, the first contains the report on the somatic affinities of the tribes and castes of India as shown in the series of measurements which have been taken from time to time by Dr. B. S. Guha, anthropologist of the Zoological. Survey. This report is of no little moment to the anthropologist. It restates the racial problem of India in the light of the most recent research; and not only does it review the evidence afforded by recent investigation in the prehistory of India, especially with reference to the composition of the calcholithic population of the Indus valley, but it also advances evidence against certain of the racial theories put forward by Sir H. H. Risley a generation ago, which, in a general sense, have held the field ever since.

Dr. Guha's investigations occupied from 1930 until 1933, during which period he toured the greater part of Central, Western and Southern India, and visited selected areas in the north and east, covering in all some ten thousand miles. Thirty-four racial groups were examined, of which fourteen were Brahmin, sixteen belonged to various Hindu castes, and four groups were tribal. The objective of the examination was to obtain particulars of the somatic characters of the Brahmins with the castes next in order of precedence, and of the so-called lowest castes and the major aboriginal groups in the survey. This distribution of inquiry, it was thought, would reveal the racial types present among the highest and the lowest classes of the Indian population, and the extent of intermixture between $(a)$ Brahmins and the upper classes of the rest of the population, and $(b)$ between the latter and the aboriginal tribes. The method of investigation followed has been by extraction of the reduced coefficients of racial likeness.

Dr. Guha discusses his material in detail in groups constituted on the basis of topography and the known history of the country. This analysis contains much material in highly condensed form bearing on the special problems of the inquiry. For details reference must be made to the original. Here it is not proposed to do more than mention briefly the main conclusions relating to racial classification and racial history.

Three eloments are discerned in the racial composition of the peoples of India :

(A) A short-statured, long-headed element, with high cranial vault, faintly marked orbital ridges, and broad, short, orthognathous face, with medium lips and a prominent, long nose, having moderately spread alæ, the skin-colour varying from light brown to dark tawny, the hair being black, straight inclined to wavy, and moderate in amount on both face and body. This is the predominant type in the

* Census of India, 1931. Vol. 1 : India. Part 3: Ethnographical. A : Racial Affinities of the Peoples of India, by Dr. B. S. Guha; B : Ethnographic Notes, by various Authors, edited by J. H. Hutton. 7.10 rupees; 138 . greater part of the lower stratum of the population of Northern India, including to some extent the Punjab.

On this basic substratum there appears to have been imposed the two following :

$(B)$ In the western littoral and Bengal, a brachycephalic element of medium stature, with flattened occiput, but having also a high head and, not infrequently, a receding forehead. The face is short and orthognathous, but broader than in $(A)$. The nose is long and highly pitched, but quite often arched and convex. The skin-colour varies from pale white to light brown. A small percentage has light eyes and a small proportion has dark brown hair. The hair is generally straight and the pilous system well developed.

(C) In Northern India, a long-hoaded strain with a comparatively lower but longer head, and tall stature. It has a long face and long prominent narrow nose. In its purest form it is found among Kaffirs and Pathans, where the skin-colour is predominantly rosy white, and an appreciable number have grey-blue eyes. In the plains of Northern India, among Sikhs of the Punjab and Brahmins of the United Provinces, the skin-colour changes to a transparent light brown. Here too a few have light eyes and brown hair. The pilous system is well developed.

Type $A$ may be a south-eastward drift of a very early type of modern man, which reached India in very early times, while $C$ may be a late drift from the north-west.

In addition to these three types, the aboriginal population discloses four types:

$(D)$ A short, long- and moderately high-headed strain, with strongly marked eyebrow ridges, hair that varies from wavy to curly, and a skin that is dark chocolate brown, approaching black. This is predominant among the aboriginal tribes of central and southerm India, and is closely allied to the Veddas of Ceylon, Toala of Celebes, Semang of the Malay Peninsula, and the Australian aborigines.

(E) A dark pygmy type having spirally curved hair, which is mostly submerged in India at the present time.

(F) A brachycephalic mongolid type, constituting the main population of the sub-Himalayan region. What is probably a sub-type $\left(F^{1}\right)$ is the dominant element in Burma, but it has strong affinities with Siamese, Malays and Cochin Chinese.

$(G)$ In Assam and Northern Burma there seems to have entered a second Mongolid strain of medium stature, longish head and medium nose. The Angami Nagas may be considered the best representatives of this type.

The evidence of anthropometry, it is noted, does not show that the mongolid racial strain entered in any considerable degree into the population of the mainlands of India. The true Mongol element remains outside the Indian frontiers.

There is a lack of the skeletal material which would make it possible to trace the history of these types. Dr. Guha, who ably summarises the archæological evidence, argues for the essential continuity in geographical distribution of the megalithic culture from neolithic Sind to Southern India, dating it in the 
latter area in the Iron Age. Iron was introduced into Northern India by the Vedic Arya about 1500 B.C., who drove the previous inhabitants towards Central and Southern India, where the 'black' metal and the horse are associated with invaders from the north.

Prehistoric skeletal remains fall into two groups, (a) the calcholithic, from the Indus Valley, especially Mohenjo-daro and Harappa; and (b) Iron Age.

The majority of the skeletal remains of the calcholithic Indus valley civilisation are dolichocranial, but show evidence of two long-headed races, of which one has a much larger skull, but with lower cranial vault and marked post auricular development. At first classed as Proto-Australoid, it is now regarded as 'Caucasic'. A third race, most strongly represented at Harappa, is brachycephalic, showing Armenoid affinities.

The skulls of the scanty Iron Age remains show Australoid, Mediterranean and Armenoid affinities. It is suggested that late in the Iron Age the Peninsula was occupied by a long-headed high-skulled race with a low broad face, comparable to the Combe Capelle type, and further that this type is to be associated with the megalithic culture. Apparently it absorbed a negrito element and later had superimposed on it a race with Armenoid affinities.

The racial history of the Indian peoples may then be summarised as follows :

At the beginning of the fourth millennium B.C., Northern India was occupied by a long-headed race with high cranial vault and long narrow face, by its side being a second, powerfully built, race, also longheaded, but with distinctive peculiarities. With these was a third race showing Armenoid affinities, probably a later influx. None of these had as yet penetrated Southern India. Possibly as early as the neolithic age the megalithic culture had been introduced by people of the Combe Capelle type, who afterwards in the Iron Age reached Southern India, where they subdued the aborigines, but themselves were overrun later by people of Armenoid affinities. In the north they mingled with the Mediterraneans of the Indus Valley to form the bulk of the population of Peninsular and Northern India of to-day. In the upper classes of Northern India another strain, with undoubted northern affinities, is clearly to be distinguished, which, as E. Fischer says, retains the Nordic characters, but without the fair tint of the skin. This strain in fact is also retained slightly among Tamil Brahmins in the south; but it is especially evident among the Chitpavan, or Maharashtra, Brahmins, who constitute one of the fairest groups in India. It is probable that the powerfully built large-headed strain at Mohenjo-daro forms one of the constituents of this race, whose advent to India appears to synchronise with the 'Aryan' invasion.

The brachycephalic element dominant in the west and south-west of India and also in Bengal to-day, which is definitely non-Mongolic in character, possibly drifted into Bengal before it reached Southern India. Its occurrence at Mohenjo-daro and Harappa is definitely against the view that it is a Tokharianspeaking race from the Pamirs. It is comparable to the brachycephalic element in southern Arabia, which Keith identified in the records of Bertram Thomas.

\section{The Upper}

$\mathrm{I}^{\mathrm{N}}$ the Joule Memorial Lecture delivered to the Literary and Philosophical Society of Manchester on February 11, Prof. E. V. Appleton said that it was perhaps not inappropriate, in a lecture associated with a great pioneer in thermal measurements, to survey recent advances in our knowledge concerning the temperature of the upper air. Frictional work produces heat, as is well known, and Joule was the first to state the exact nature of this equivalerree. An example of the heating process studied by Joule is the flight of a meteor through the atmosphere, in which case the energy of its speed is ultimately transformed into heat and light. But it has been found that electric waves can also heat the atmosphere when they travel through it. Ultra-violet light from the sun, for example, produces a belt of hot air at about the level in the ionosphere $(300 \mathrm{~km}$. high) where short wireless waves are reflected. It has also been found that a powerful long-wave wireless station can warm up the Kennelly-Heaviside layer to a very small but still detectable extent. The so-called 'Luxembourg effect' noticed by long-distance listeners, who find that they receive a long-wave programme when their receiver is tuned to the medium waves, can be traced to the influence of such a process.

It is a familiar fact that the temperature of the air falls as we go upwards from sea-level. But the temperature does not go on decreasing, as Teisserenc de Bort first showed by experiments with free

\section{Atmosphere}

balloons. At a height which varies from $16 \mathrm{~km}$. at the equator to $6 \mathrm{~km}$. at the poles, the fall of temperature is arrested. It is at this level that the stratosphere begins, the underlying stratum being called the troposphere.

At first it was assumed that the stratospheric temperature of $-53^{\circ} \mathrm{C}$. is maintained up to the highest levels, and it eame as quite a shock when Lindemann and Dobson announced, in 1922, that their study of the tracks of meteors in the atmosphere had led them to conclude that the air at $60 \mathrm{~km}$. in height must be $30^{\circ}$ C.- a temperature higher even than that obtaining at ground-level. Experiments on the anomalous propagation of sound from explosions and gunfire had shown that sound waves were reflected at this warm level. The sound of a gun at Shoeburyness, for example, would be expected to travel to Birmingham in a little more than ten minutes and yet the measured time, due to the upperair trajectory pursued by the waves, was found to be twelve minutes.

In the electrically conducting region of the atmosphere, the daily sequence of events has been studied by means of radio-wave exploration. Conditions do not change much from summer to winter at the $100 \mathrm{~km}$. level, but there appears to be a very pronounced seasonal variation of temperature at $300 \mathrm{~km}$. In summer the ionisation at that level is abnormally low, whereas theory would suggest that it should be 